\title{
Coordination policy for a three echelon supply chain considering imperfect quality items
}

\author{
Narayan Singh", Bindu Vaish and S. R. Singh
}

Department of Mathematics D.N. College, C.C.S. University, Meerut (U.P), India-250001

\section{CHRON I C L E}

\section{Article history:}

Received October 262013

Received in Revised Format

July 52014

Accepted July 52014

Available online

July 72014

Keywords:

Three echelon supply chain

Imperfect production process

Backlogging \begin{abstract}
A B S T R A C T
In this study, we develop a three echelon supply chain model for items to determine the optimal reliability and production rate, which achieves the biggest total integrated profit for an imperfect manufacturing process. Here, we have taken a supplier, a manufacturer and a retailer in which supplier supplies raw materials to manufacturer, manufacturer produces perfect and imperfect quality items because practically it happens and manufacturer supplies perfect quality items to the retailers. In production system, production facility may shift from an in-control state to an out-ofcontrol state at any random time. The basic assumption of classical economic manufacturing quantity model is that all manufacturing items are of perfect quality but the assumption is not true in practice. The proposed study is formulated assuming that a certain percent of total product is defective. This percentage also varies with production rate and production run time. The defective items are restored in original quality by reworked at some costs to maintain the quality of products in a competitive market. Finally, numerical example and its graphical representation are given to illustrate the proposed model. Sensitivity analysis is also provided to test feasibility of the model.
\end{abstract}

\section{Introduction}

The production or the distribution of inventories is an activity in which almost all organizations are involved. It seems that there is a great economic incentive to optimize the inventories across process supply chain. To accomplish this objective the main challenge is how to effectively integrate inventory management with network design for multi-echelon process supply chain so that decision on locations to stock the inventory and the associated amount of inventories can be determined simultaneously to minimize costs. The integration is non-trivial for multi-echelon supply chains and their associated inventory systems in the presence of uncertain customer demands.

A large amount of researches on multi-echelon inventory control has appeared in the literature during the last decades. Clark and Scarf (1960) were the first to present the concept of serial multi-echelon structures to determine the optimal policy. Banerjee (1986) derived a joint economic lot size model for a single vendor, single buyer system where the vendor has a finite production rate. The competitive framework stipulates that firms tend to emphasize certain competitive dimensions and develop manufacturing capabilities to achieve the chosen dimensions to enhance their market position. The * Corresponding author.

E-mail: narayansingh1980@gmail.com (N. Singh)

(C) 2014 Growing Science Ltd. All rights reserved. doi: $10.5267 /$ j.jijiec.2014.7.001 
competitive dimensions are cost, quality, delivery and flexibility. These dimensions relate the production process and control with technology, capacity, facilities, planning, etc. This research assesses the impact of product rate, and production run time of the systems, inventory level and order fill rates. In traditional economic order quantity (EOQ) and economic production quantity (EPQ) model, all items are perfect. It is common to all industries that a certain percent of produced/ordered items are non-conforming (imperfect) quality. In this direction, Rosenblatt and Lee (1986) studied a model where the probability distribution of the time of shifting from in-control state to out-of-control state follows an exponential distribution. They assumed that the defective items produced in out-ofcontrol state could be reworked instantaneously at a cost and found that the presence of defective products results in smaller lot size.

On the basis of RL model, Lee and Rosenblatt (1987) showed that process inspection during the production-run time can detect the shifting time and it could be restored earlier. Cheng (1989) studied an inventory model for imperfect production process and quality dependent unit production cost. Khouja and Mehrez (1994) addressed the effects of variable production rate and imperfect quality on economic production lot size model. Khouja (1999) studied the economic lot size production (ELSP) with a controllable production rate and imperfect quality. Ben-Daya and Hariga (2000) developed a model for ELSP with imperfect processes and process restoration. Other factors, such as damages and breakages during the handling process may also result in defective items. These considerations were discussed by Salameh and Jaber (2000) who are among the first few authors to consider imperfect quality. The above surveyed works assumed imperfect production processes that generate defects that are either reworked or scrapped.

Unlike these works, Salameh and Jaber (2000) developed an extended EOQ model where imperfect quality items are salvaged at a discounted price. Incoming lots of raw material containing items of imperfect quality that occur as a random fraction with a known probability distribution, undergo a screening in which defective items in the lot are removed by the end of the screening period and sold at a discounted price. Chung and Hou (2003) developed a model to determine an optimal production run time with imperfect production processes and allowable shortage. In the model of Wang (2004), an imperfect EMQ model for production which are repaired and sold under a free-repair warranty policy (i.e., the cost incurred by a defective item after its sale) discussed by Yeh et al. (2000) has been extended to consider general shift distribution.

Sheu and Chen (2004) have developed a lot-sizing model to determine the level of preventive maintenance for an imperfect process control. Jaber and Guiffrida (2004) have developed the quality learning curve which is a composite learning curve consisting of the sum of two learning curves. The first learning curve describes the reduction in time for each additional unit produced, while the second learning curve describes the reduction in time for each additional defective unit reworked. Eroglu and Ozdemir (2007) have extended the model of Salameh and Jaber (2000) by incorporating full backordered in stock out situation and the defective items as a collection of imperfect and scrap items. Liao (2007) has investigated an imperfect production process that requires production corrections and imperfect maintenance. Two states of production process are occur, namely state out-of-control state and state in-control state. In 'out-of-control' state, the product is not perfect and a part is rejected (reworking is impossible) with a probability q. The product is perfect (good quality) with a probability $(1-q)$.

Lo et al. (2007) have extended a production-inventory model in aspect of both the manufacturer and the retailer. They have assumed a varying rate of deterioration, partial back-ordering, inflation, imperfect production process and multiple deliveries. The elapsed time for the production process shift to imperfect production is assumed to be exponential distribution have modelled an Economic Production Lot size model for imperfect items in which production rate is considered as fixed quantity and the demand rate is probabilistic under certain budget and shortage constraints. Chiu et al. (2007) 
discussed a lot size problem with random scrap rate and backlogging by alternative approach instead of calculated method. Sarker et al. (2008) addressed the issue relating to reworking of defective items in a multi-stage production system by considering two operational policies: reworking of defective items within the same cycle and after $N$ cycles. Biswas and Sarker (2008) studied an optimal batch quantity model with rework and scrap and detected the scraps after production in three ways with the assumption that once the scrap is detected, it is discarded immediately. Lee (2008) has developed a maintenance model in multi-level multi-stage system.

According to his model, the investment in preventive maintenance is to reduce the variance and the deviation of the mean from the target value of the quality characteristics that reduce the proportion of defectives also to increase reliability of the product. Cardenas-Barron (2008) presented a simple derivation to find out optimal manufacturing batch size with rework process at single stage production system. Cardenas-Barron (2009) developed an EPQ model with planned backorders for determining the production lot size and the size of backorders in an imperfect production process where all defective items were reworked at the same cycle. Liao et al. (2009) investigated maintenance and imperfect process with EPQ model involving a deteriorating production system with an increasing hazard (failure) rate. Sana and Chaudhuri (2010), Sana (2010) and Sarkar et al. (2010) showed that the defective items could be reworked at a cost where overall production-inventory costs could be reduced significantly. Sana (2011) discussed a production inventory model of imperfect quality product in a three echelon supply chain. Sarkar (2012) analyzed an inventory model with reliability in an imperfect production process. Recently, Sana et al (2012) considered a multi-echelon supply chain model for reworkable items in multiple-markets with supply disruption. Singh et al (2012) discussed shortage in an economic production lot-size model with rework and flexibility. Sana et al (2012) developed a threelayer supply chain production inventory model for reworkable items.

In this paper, we construct a model of three-layer supply chain containing supplier, manufacturer and retailer in which complete backlogging is allowed for retailer. The average profit of the supplier is evaluated and the average profit of the manufacturer is calculated when the out-of-control state occurs or does not occur during regular production-run time. Retailer's individual average profit is also obtained. The integrated expected average profit and its difference with the total expected average profit by Stakelberg approach is calculated and a numerical example is considered to test which one is latter.

\section{Assumptions and Notations}

The following assumptions and notations are considered to develop the model.

\subsection{Assumptions}

1. Single supplier, Single manufacturer, Single retailer and single item are considered.

1. Demand rate is constant and production rate is decision variable.

2. An elapsed time until shift is arbitrarily distributed with mean and variance.

3. Lead time is assumed to be negligible.

4. During a production run, the production process may shift from in-control state to out-ofcontrol state. During out-of-control state imperfect quality items are produced and these are reworked at a cost immediately.

5. Partial backlogging is allowed for retailer and this backlogging is replenished in next delivery. Replenishments are instantaneous.

6. Multiple deliveries per order are considered. The planning horizon is infinite and the cycles during the planning horizon are continuous. Here one cycle is considered.

7. Unit production cost is a function of production rate. 
8. Defective items at supplier and manufacturer are considered which follow different probability distribution functions.

9. Cost of idle times at supplier is also assumed.

10. Joint effect of supplier, manufacturer and retailer is considered in a supply chain.

\subsection{Notations}

$P \quad$ Production rate in units per year

$Q \quad$ Replenishment lot size of supplier

$A_{s} \quad$ Set up cost of supplier

$h_{s} \quad$ Holding cost of raw materials per unit per unit time for supplier

$u \quad$ Proportional probability of defective items at supplier with probability density function $f(u)$

$r_{s} \quad$ Screening rate per unit time at supplier

$S_{s} \quad$ Screening cost per unit item at supplier

$I_{S} \quad$ Cost per unit idle time of supplier

$C_{s} \quad$ Purchasing cost per unit item of supplier

$A C_{s} \quad$ Average cost for raw material supplier

$E A C_{S} \quad$ Expected average cost of supplier

$A_{m} \quad$ Set up cost of manufacturer

$h_{m} \quad$ Holding cost of finished goods per unit per unit time for manufacturer

$S_{m} \quad$ Screening cost per unit item at manufacturer

$w_{m} \quad$ Selling price per unit perfect quality item of manufacturer

$R \quad$ Rework cost per unit

$N \quad$ Number of defective items in a production cycle

$T_{1} \quad$ The production period

$T_{2} \quad$ The non-production period

$C(P) \quad$ Unit production cost

$A C_{m} \quad$ Average cost of manufacturer

$E A C_{m} \quad$ Expected average cost of manufacturer

$D \quad$ Demand rate of retailer

$A_{r} \quad$ Set up cost of the retailer

$h_{r} \quad$ Holding cost of finished goods per unit per unit time for retailer

$B \quad$ Maximum backordering quantity for retailer

$w_{1} \quad$ Retailer's per unit backlog cost per unit time

$T_{3} \quad$ Period that a retailer is not out of stock

$T_{4} \quad$ Period that a retailer is out of stock

$T \quad$ Cycle time

$n \quad$ Number of deliveries of finished goods from manufacturer to retailer per order cycle

$A C_{r} \quad$ Average cost of retailer

$E A C_{r} \quad$ Expected average cost of retailer

\section{Formulation of the model}

The following scope applies to the study. We focused on supplier-manufacturer-retailer cooperation; there are two stages in our model. The first stage is the manufacturer production system. The manufacturer purchases raw materials from outside suppliers and delivers the fixed quantities to the manufacturer's warehouse at a fixed time interval. The manufacturer withdraws raw materials form the warehouse to produce the finished goods. The second stage is the retailer inventory system. Fixed quantity of finished goods with multiple deliveries is delivered to the retailer at a fixed-time interval. Representation of inventory level for supplier, manufacture and retailer is shown in Fig. 1(a), Fig. 1(b) and Fig. 1(c), respectively. 


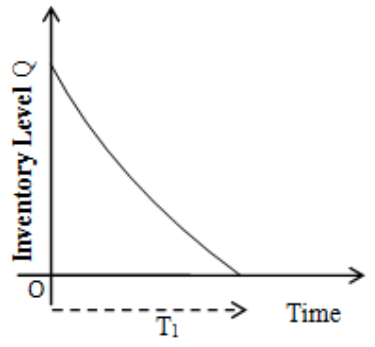

Fig. 1(a)

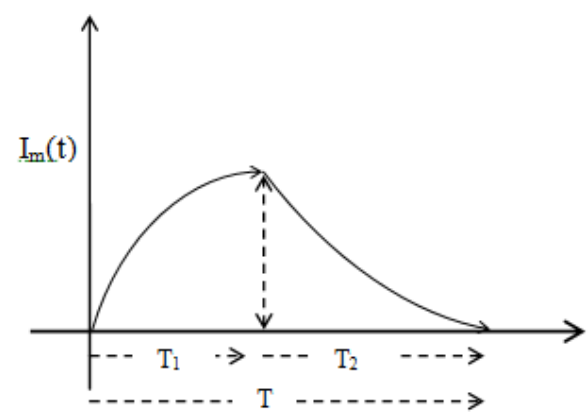

Fig. 1(b)

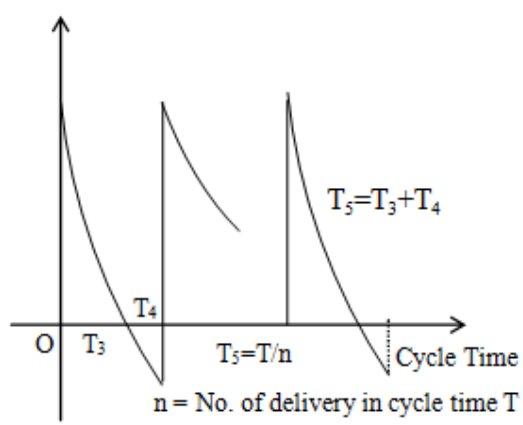

Fig. 1(c)

Fig. 1. inventory level with respect to time for supplier, manufacturer and retailer

This study develops an integrated inventory model for perfect and imperfect items under a multi echelon supply chain environment. A mathematical model with integrating single supplier, single manufacturer and single retailer is derived to obtain the optimal production rate and order lot-size when the joint total cost of the supplier, the manufacturer and retailer is minimized.

\subsection{Supplier's individual inventory model}

Supplier supplies the raw material at rate $P$ to the manufacturer up to production run time $T_{1}$. The lot size $Q$ is screened with rate $r_{s}$ at cost $S_{s}$ per unit item, after completion of screening, the total defective items are sent back the vendors where supplier purchased at a sales price $\mathrm{w}_{\mathrm{s}}$ per unit item. $I_{S}(t)$ represent inventory level of good items at any time $t$. The governing differential equation is

$\frac{d I_{s}(t)}{d t}=-P \quad 0 \leq t \leq T_{1}$ with $\quad I_{s}(0)=(1-u) Q$ and $I_{s}\left(T_{1}\right)=0$

From above eq., we have

$$
I_{s}(t)=(1-u) Q-P t \quad 0 \leq t \leq T_{1} \text { and } \quad T_{1}=\frac{(1-u) Q}{P} \quad\left(\text { from } I_{s}\left(T_{1}\right)=0\right)
$$

The inventory holding cost of perfect quality items is

$h_{s} \int_{0}^{T_{1}} I_{s}(t)=h_{s}\left\{(1-u) Q T_{1}-\frac{1}{2} P T_{1}^{2}\right\}=\frac{1}{2} h_{s} \frac{(1-u)^{2} Q^{2}}{P}$

The inventory holding cost of imperfect quality items is $u h_{s} Q\left(\frac{Q}{r_{s}}\right)$ the screening cost is $S_{s} Q$,

The purchasing cost of Q items is $C_{s} Q$ and the cost for idle time is $\left(T-T_{1}\right) I_{s}$

The average cost of supplier is $=\frac{1}{T}[$ set up cost + inventory holding cost + screening cost + purchasing cost + cost for idle time]

$$
\begin{aligned}
& A C_{s}=\frac{1}{T}\left[A_{s}+h_{s}\left\{\frac{(1-u)^{2} Q^{2}}{2 P}+\frac{u Q^{2}}{r_{s}}\right\}+\left(S_{s}+C_{s}\right) Q+\left(T-T_{1}\right) I_{s}\right] \\
& A C_{s}=\frac{A_{s} D}{(1-u) Q}+\left(\frac{h_{s}(1-u) D}{2 P}+\frac{h_{s} u D}{r_{s}(1-u)}\right) Q+\frac{\left(S_{s}+C_{s}\right) D}{(1-u)}+I_{s}-\frac{D I_{s}}{P}
\end{aligned}
$$

\subsection{Manufacturer's individual inventory model}

The manufacturer's inventory system can be divided into two independent phase depicted by $\mathrm{T}_{1}$ and $\mathrm{T}_{2}$. The production starts with the rate $\mathrm{P}$ at the time $t=0$ and continuous up to time $\mathrm{T}_{1}$. During time span 
$\left[0, T_{1}\right]$ inventory piles up, adjusting demand $D$ of the retailer. At the time $t=T_{1}$, the stock of inventory is $(P-D) T_{1}$. During time $\operatorname{span}\left[0, T_{2}\right]$, this stock level depletes satisfying the demand of retailer and it reaches at zero level at time $\mathrm{T}_{2}$. The governing differential equations are

$\frac{d I_{m 1}(t)}{d t}=P-D$ where $0 \leq t \leq T_{1}$ with $I_{m 1}(0)=0$

and

$\frac{d I_{m 2}(t)}{d t}=-D \quad$ where $\quad T_{1} \leq t \leq T$ with $I_{m 2}(T)=0$

Solving the above equations, we find

$I_{m 1}(t)=(P-D) t \quad 0 \leq t \leq T_{1} \quad$ and $\quad I_{m 2}(t)=P T_{1}-D t \quad T_{1} \leq t \leq T$

where

$I_{m 2}(T)=0$ implies $T=\frac{P T_{1}}{D}=\frac{(1-u) Q}{D}$

The screening cost is $S_{m} P T_{1}=S_{m} D T$, The inventory holding cost is

$H_{m}=h_{m}\left\{\int_{0}^{T_{1}}(P-D) t d t+\int_{T_{1}}^{T}\left(P T_{1}-D t\right) d t\right\}=h_{m}(1-u) Q \frac{(P-D)}{2 P} T$

In the model, the production process is so adjusted that the produced items at the beginning of the production are conforming quality up to a certain time $\tau$ (in-control state) after this the production process shift to an out-of-control state. In out-of-control state, some of the produced items are nonconforming quality. The production rate of defective items is $\lambda(\mathrm{t}, \tau, \mathrm{P})$ percent of production rate $P$. Here $\lambda(\mathrm{t}, \tau, \mathrm{P})$ is defined as

$\lambda(\mathrm{t}, \tau, \mathrm{P})=\alpha \mathrm{P}^{\beta}(t-\tau)^{\gamma}$ where $\beta \geq 0, \gamma \geq 0$ and $t \geq \tau$

Generally speaking, the percentage of defective items increases with increase of production rate and production run time. The formulation of the function $\lambda(\mathrm{t}, \tau, \mathrm{P})$ shows that it is an increasing function of production rate and production run time simultaneously. Therefore, the total defective items during $[0, \tau]$ is zero and during $\left[\tau, T_{1}\right]$ is

$$
\mathrm{N}=\mathrm{P} \int_{\tau}^{T_{1}} \alpha \mathrm{P}^{\beta}(t-\tau)^{\gamma} d t=\frac{\alpha}{(\gamma+1)} \mathrm{P}^{\beta+1}\left(T_{1}-\tau\right)^{\gamma+1}
$$

Therefore, the total defective items in the cycle is

$$
N=\left\{\begin{array}{ccc}
0 & \text { if } & \tau \geq T_{1} \\
\frac{\alpha}{(\gamma+1)} \mathrm{P}^{\beta+1}\left(T_{1}-\tau\right)^{\gamma+1} & \text { if } & \tau \leq T_{1}
\end{array}\right.
$$

The distribution function for out of control state is $G(\tau)=1-e^{-g(P) \tau}$ such that 
$\int_{0}^{\infty} d G(\tau)=g(P) \int_{0}^{\infty} e^{-g(P) \tau} d \tau=1$. The exponential distribution has often been used to describe the elapsed time to failure of many components of the machinery system. The mean time to failure, $1 / \mathrm{g}(\mathrm{P})$, is a decreasing function of $\mathrm{P}$. Therefore, the expected number of defective items in a production lot size $\mathrm{Q}$ is

$E(N)=\frac{\alpha}{(\gamma+1)} \mathrm{P}^{\beta+1} \int_{0}^{T_{1}}\left(T_{1}-\tau\right)^{\gamma+1} d G(\tau)=\frac{\alpha}{(\gamma+1)} \mathrm{P}^{\beta+1} \int_{0}^{T_{1}}\left(T_{1}-\tau\right)^{\gamma+1} g(P) e^{-g(P) \tau} d \tau$ (Singh et al. 2012)

If $\gamma \rightarrow 0$, then $E(N) \cong \frac{1}{2} \alpha \mathrm{P}^{\beta-1}(1-u) g(P) Q D T$

So the rework cost is $R E(N)$ where $E(N)$ is the expected number of defective items.

The unit production cost is

$C(P)=K_{m}+L+\frac{V}{P^{\theta}}+\eta P^{\delta}$ (Singh et al. 2012)

where $K_{m}$ the material cost per unit item, $\mathrm{L}$ is the advertisement cost per unit item, $\mathrm{V}$ is the total labour/energy cost per unit time of a production system which is equally distributed over the unit time. So, $\frac{V}{P^{\theta}}$ describe with $\mathrm{P}$ increase and the term $\eta P^{\delta}(\delta>0)$ is the total die costs that is proportional to the positive power of the production rate $(\mathrm{P})$. In short run process, total cost and average cost of production decrease with increase of production rate P. Because, in the early stage of production, utilization of fixed cost factors are properly utilized. So sharing of fixed factors gradually decline with production rate. But in long run process, all factors of production are variable. In this case there are many external and internal factors which accelerate the cost of process. It is rationale that proportional charges of fixed factors with variable are not possible. This disproportional combination between fixed and variable may enhance the cost of production. That is why the cost function is U-shaped.

The average cost of manufacturer is $=\frac{1}{T}[$ set up cost + screening cost + poduction cost + inventory holding cost + Rework cost ]

$$
\begin{aligned}
& A C_{m}=\frac{1}{T}\left[A_{m}+S_{m} D T+Q C(P)+H_{m}+R E(N)\right] \\
& A C_{m}=\frac{A_{m} D}{(1-u) Q}+S_{m} D+\frac{D}{(1-u)}\left(K_{m}+L+\frac{V}{P^{\theta}}+\eta P^{\delta}\right)+h_{m}(1-u) Q \frac{(P-D)}{2 P}+\frac{1}{2} \alpha R \mathrm{P}^{\beta-1}(1-u) g(P) Q D
\end{aligned}
$$

\subsection{Retailer's individual inventory model}

The retailer's inventory system can be represented by the following differential equations;

$\frac{d I_{r 1}(t)}{d t}=-D$ where $0 \leq t \leq T_{3}$ with $I_{r 1}\left(T_{3}\right)=0$

and

$\frac{d I_{r 2}(t)}{d t}=-B$ where $\quad 0 \leq t \leq T_{4}$ with $I_{r 2}(0)=0$

Solving the above equations, we find 
$I_{r 1}(t)=\left(T_{3}-t\right) D \quad 0 \leq t \leq T_{3} \quad$ and $\quad I_{r 2}(t)=-B t \quad 0 \leq t \leq T_{4} \quad($ where $B<D)$

Now

$I_{r 1}(0)=\frac{Q}{n}$ implies $\quad T_{3}=\frac{Q}{n D}$

The inventory holding cost is $\frac{1}{2} h_{r} D T_{3}^{2}$, the unit purchasing cost is $w_{m} \frac{Q}{n}$

and the shortage cost occur during $\mathrm{T}_{4}$ is $\frac{1}{2} w_{1} B T_{4}^{2}$ where $T_{4}=\frac{B}{D}$

There are $n$ deliveries per cycle. The fixed time interval between the deliveries is $\mathrm{T} / \mathrm{n}$.

The average cost of retailer is $=$

$\frac{n}{T}[$ set up cost + unit purchasing cost + inventory holding cost + shortage cost $]$

$A C_{r}=\frac{n}{T}\left[A_{r}+w_{m} \frac{Q}{n}+\frac{1}{2} h_{r} D T_{3}^{2}+\frac{1}{2} w_{1} B T_{4}^{2}\right]$
$A C_{r}=\frac{n A_{r} D}{(1-u) Q}+\frac{w_{m} D}{(1-u)}+\frac{h_{r} Q}{2 n(1-u)}+\frac{n w_{1} B^{3}}{2(1-u) D Q}$

\subsection{Stakelberg Approach}

In this three echelon supply chain, manufacturer is the main component. Manufacturer leads the system and supplier, retailer and other parties follow the manufacturer.

Using $T_{1}=\frac{(1-u) Q}{P}$ and $T=\frac{P T_{1}}{D}=\frac{(1-u) Q}{D}$

The expected average cost of supplier is $E_{A C}(P, Q)=E\left[\mathrm{AC}_{s}\right]$

$E\left[A C_{s}\right]=\frac{A_{s} D}{Q} E\left(\frac{1}{1-u}\right)+\left(\frac{h_{s} D E(1-u)}{2 P}+\frac{h_{s} D}{r_{s}} E\left(\frac{u}{1-u}\right)\right) Q+\left(S_{s}+C_{s}\right) D E\left(\frac{1}{1-u}\right)+I_{s}-\frac{D I_{s}}{P}=1_{s 0}+\frac{1_{s 1}}{Q}+1_{s 2} \frac{Q}{P}+1_{s 3} Q-\frac{1_{s 4}}{P}$

where

$1_{s 0}=I_{s}+\left(S_{s}+C_{s}\right) D E\left(\frac{1}{1-u}\right), 1_{s 1}=A_{s} D E\left(\frac{1}{1-u}\right), 1_{s 2}=\frac{h_{s} D E(1-u)}{2}, 1_{s 3}=\frac{h_{s} D}{r_{s}} E\left(\frac{u}{1-u}\right), 1_{s 4}=D I_{s}$

The expected average cost of manufacturer is $E A C_{m}(P, Q)=E\left[\mathrm{AC}_{m}\right]$

$$
\begin{aligned}
& E\left[A C_{m}\right]=\frac{A_{m} D}{Q} E\left(\frac{1}{1-u}\right)+S_{m} D+D E\left(\frac{1}{1-u}\right)\left(K_{m}+L+\frac{V}{P^{\theta}}+\eta P^{\delta}\right) \\
& +h_{m} E(1-u) Q \frac{(P-D)}{2 P}+\frac{1}{2} \alpha R \mathrm{P}^{\beta-1} E(1-u) g(P) Q D \\
& =l_{m 0}+l_{m 1} Q+\frac{l_{m 2}}{Q}-l_{m 3} \frac{Q}{P}+l_{m 4} P^{\delta}+\frac{l_{m 5}}{P^{\theta}}+l_{m 6} Q P^{\beta-1} g(P)
\end{aligned}
$$

where

$$
\begin{aligned}
& l_{m 0}=S_{m} D+D\left(K_{m}+L\right) E\left(\frac{1}{1-u}\right), l_{m 1}=\frac{1}{2} h_{m} E(1-u) \quad l_{m 2}=A_{m} D E\left(\frac{1}{1-u}\right) \quad l_{m 3}=\frac{1}{2} h_{m} D E(1-u) \\
& l_{m 4}=\eta D E\left(\frac{1}{1-u}\right), \quad l_{m 5}=V D E\left(\frac{1}{1-u}\right), \quad l_{m 6}=\frac{1}{2} \alpha R E(1-u) D
\end{aligned}
$$


The expected average cost of retailer is $E A C_{r}(Q)=E\left[\mathrm{AC}_{r}\right]$

$$
\begin{aligned}
E\left[A C_{r}\right] & =\frac{n A_{r} D}{Q} E\left(\frac{1}{1-u}\right)+w_{m} D E\left(\frac{1}{1-u}\right)+\frac{h_{r} Q}{2 n} E\left(\frac{1}{1-u}\right)+\frac{n w_{1} B^{3}}{2 D Q} E\left(\frac{1}{1-u}\right) \\
& =l_{r 0}+l_{r 1} Q+\frac{l_{r 2}}{Q}
\end{aligned}
$$

where

$l_{r 0}=w_{m} D E\left(\frac{1}{1-u}\right) \quad l_{r 1}=\frac{h_{r}}{2 n} E\left(\frac{1}{1-u}\right) \quad l_{r 2}=n\left(A_{r} D+\frac{w_{1} B^{3}}{2 D}\right) E\left(\frac{1}{1-u}\right)$

For optimum value of $E A C_{m}$,

$\frac{\partial E A C_{m}}{\partial P}=\frac{\partial E A C_{m}}{\partial Q}=0$

Therefore,

$\frac{\partial E A C_{m}}{\partial P}=l_{m 3} \frac{Q}{P^{2}}+2 l_{m 4} P-\frac{l_{m 5}}{P^{2}}=0 \quad$ or $\quad l_{m 3} Q++2 l_{m 4} P^{3}-l_{m 5}=0$

$\frac{\partial E A C_{m}}{\partial Q}=l_{m 1}-\frac{l_{m 2}}{Q^{2}}-l_{m 3} \frac{1}{P}+a l_{m 6}=0 \quad$ or $\quad\left(l_{m 1}+a l_{m 6}\right) P Q^{2}-l_{m 2} P-l_{m 3} Q^{2}=0$

Again differentiating, we have

$$
\begin{aligned}
& \frac{\partial^{2} E A C_{m}}{\partial P^{2}}=-2 l_{m 3} \frac{Q}{P^{3}}+2 l_{m 4}+\frac{2 l_{m 5}}{P^{3}} \\
& \frac{\partial^{2} E A C_{m}}{\partial Q^{2}}=\frac{2 l_{m 2}}{Q^{3}} \text { and } \quad \frac{\partial^{2} E A C_{m}}{\partial P \partial Q}=\frac{l_{m 3}}{P^{2}}
\end{aligned}
$$

Solving the above equation, we have value of $(\mathrm{P}, \mathrm{Q})$, say $\left(P_{m}^{*}, Q_{m}^{*}\right)$

If $\left(\frac{\partial^{2} E A C_{m}}{\partial P^{2}}\right)\left(\frac{\partial^{2} E A C_{m}}{\partial Q^{2}}\right)-\left(\frac{\partial^{2} E A C_{m}}{\partial P \partial Q}\right)^{2}>0$ and $\frac{\partial^{2} E A C_{m}}{\partial P^{2}}>0$ hold at $\left(P_{m}^{*}, Q_{m}^{*}\right)$, the $E A C_{m}$ is minimum at $\left(P_{m}^{*}, Q_{m}^{*}\right)$

Now finally find the minimum expected total cost of supplier, manufacturer and retailer at $\left(P_{m}^{*}, Q_{m}^{*}\right)$ from the equations.

\subsection{Integrated expected average cost}

The integrated expected average cost of the supply chain is

$$
\begin{gathered}
E[I A C]=E I A C=E\left[A C_{s}+A C_{m}+A C_{r}\right] \\
=\frac{A_{s} D}{Q} E\left(\frac{1}{1-u}\right)+\left(\frac{h_{s} D E(1-u)}{2 P}+\frac{h_{s} D}{r_{s}} E\left(\frac{u}{1-u}\right)\right) Q+\left(S_{s}+C_{s}\right) D E\left(\frac{1}{1-u}\right)+I_{s}-\frac{D I_{s}}{P} \\
+\frac{A_{m} D}{Q} E\left(\frac{1}{1-u}\right)+S_{m} D+D E\left(\frac{1}{1-u}\right)\left(K_{m}+L+\frac{V}{P^{\theta}}+\eta P^{\delta}\right)+h_{m} E(1-u) Q \frac{(P-D)}{2 P} \\
+\frac{A_{r} D}{Q} E\left(\frac{1}{1-u}\right)+\frac{w_{m} D}{n} E\left(\frac{1}{1-u}\right)+\frac{h_{r} Q}{2 n^{2}} E\left(\frac{1}{1-u}\right)+\frac{w_{1} B^{3}}{2 D Q} E\left(\frac{1}{1-u}\right)+\frac{1}{2} \alpha R \mathrm{P}^{\beta-1} E(1-u) g(P) Q D
\end{gathered}
$$


598

$$
E I A C=m_{0}+m_{1} Q+m_{2} \frac{1}{Q}+m_{3} \frac{Q}{P}+m_{4} \frac{1}{P}+m_{5} P^{\delta}+m_{6} \frac{1}{P^{\theta}}+m_{7} Q P^{(\beta-1)} g(P)
$$

where

$$
\begin{aligned}
& m_{0}=I_{s}+\left(S_{s}+C_{s}\right) D E\left(\frac{1}{1-u}\right)+S_{m} D+D\left(K_{m}+L\right) E\left(\frac{1}{1-u}\right)+w_{m} D E\left(\frac{1}{1-u}\right) \\
& m_{1}=\frac{h_{s} D}{r_{s}} E\left(\frac{u}{1-u}\right)+\frac{1}{2} h_{m} E(1-u)+\frac{h_{r}}{2 n} E\left(\frac{1}{1-u}\right) \\
& m_{2}=A_{s} D E\left(\frac{1}{1-u}\right)+A_{m} D E\left(\frac{1}{1-u}\right)+n\left(A_{r} D+\frac{w_{1} B^{3}}{2 D}\right) E\left(\frac{1}{1-u}\right) m_{3}=\frac{h_{s} D E(1-u)}{2}-\frac{1}{2} h_{m} D E(1-u) \\
& m_{4}=-D I_{s}, \quad m_{5}=\eta D E\left(\frac{1}{1-u}\right), m_{6}=V D E\left(\frac{1}{1-u}\right), m_{7}=\frac{1}{2} \alpha R E(1-u) D
\end{aligned}
$$

By setting $g(P)=a P$ where $a<<1$

Now differentiating EIAC partially, we have

$$
\begin{aligned}
& \frac{\partial E I A C}{\partial P}=-m_{3} \frac{Q}{P^{2}}-m_{4} \frac{1}{P^{2}}+\delta m_{5} P^{(\delta-1)}-\theta m_{6} \frac{1}{P^{(\theta+1)}}+a \beta m_{7} Q P^{(\beta-1)} \\
& \frac{\partial E I A C}{\partial Q}=m_{1}-m_{2} \frac{1}{Q^{2}}+m_{3} \frac{1}{P}+a m_{7} P^{\beta} \\
& \frac{\partial^{2} E I A C}{\partial P^{2}}=2 m_{3} \frac{Q}{P^{3}}+2 m_{4} \frac{1}{P^{3}}+\delta(\delta-1) m_{5} P^{(\delta-2)}+\theta(\theta+1) m_{6} \frac{1}{P^{(\theta+2)}}+a \beta(\beta-1) m_{7} Q P^{(\beta-2)} \\
& \frac{\partial^{2} E I A C}{\partial Q^{2}}=2 m_{2} \frac{1}{Q^{3}}, \frac{\partial^{2} E I A C}{\partial P \partial Q}=-m_{3} \frac{1}{P^{2}}+a \beta m_{7} P^{(\beta-1)}
\end{aligned}
$$

Taking $\theta=1, \delta=2$ and $\beta=1$

For optimum value of $E I A C(P, Q), \frac{\partial E I A C}{\partial P}=\frac{\partial E I A C}{\partial Q}=0$, we have

$$
m_{3} Q-2 m_{5} P^{3}-a m_{7} Q P^{2}+\left(m_{4}+m_{6}\right)=0
$$

and

$$
m_{1} P Q^{2}+a m_{7} P^{2} Q^{2}-m_{2} P+m_{3} Q^{2}=0
$$

Now

$$
\left(\frac{\partial^{2} E I A C}{\partial P^{2}}\right)\left(\frac{\partial^{2} E I A C}{\partial Q^{2}}\right)-\left(\frac{\partial^{2} E I A C}{\partial P \partial Q}\right)^{2}=\left(2 m_{3} \frac{Q}{P^{3}}+2 m_{4} \frac{1}{P^{3}}+2 m_{5}+2 m_{6} \frac{1}{P^{3}}\right)\left(2 m_{2} \frac{1}{Q^{3}}\right)-\left(a m_{7}-m_{3} \frac{1}{P^{2}}\right)^{2}
$$

Now solving the above equations, we have value of $(P, Q)$, say $\left(P^{*}, Q^{*}\right)$

If $\left(\frac{\partial^{2} E I A C}{\partial P^{2}}\right)\left(\frac{\partial^{2} E I A C}{\partial Q^{2}}\right)-\left(\frac{\partial^{2} E I A C}{\partial P \partial Q}\right)^{2}>0$ and $\frac{\partial^{2} E I A C}{\partial P^{2}}>0$ hold at $\left(P^{*}, Q^{*}\right)$, then $E I A C$ is minimum at $\left(P^{*}, Q^{*}\right)$. 


\section{Numerical Example}

Example 1. We consider the values of parameters in appropriate units as follow: A_s $=\$ 400$, h_ $s=\$ 3$ per unit per unit time, $\mathrm{r}_{\mathrm{s}}=180,000$ units per unit time, $\mathrm{S}_{\mathrm{s}}=\$ 0.5$ per unit, $\mathrm{A}_{\mathrm{m}}=\$ 500 \overline{\mathrm{C}}_{\mathrm{s}}=\$ 25$ per unit, $\mathrm{I}_{\mathrm{s}}=\$ 300$ per unit time, $\mathrm{S}_{\mathrm{m}}=\$ 0.5$ per unit, $\mathrm{K}_{\mathrm{m}}=\$ 200, \mathrm{w}_{\mathrm{m}}=\$ 120$ per unit, $\mathrm{h}_{\mathrm{m}}=\$ 4$ per unit per unit time, $\mathrm{A}_{\mathrm{r}}=\$ 400, \mathrm{w}_{1}=\$ 20$ per unit, $\mathrm{V}=\$ 2500, \mathrm{R}=\$ 100, \theta=1 \quad \mathrm{~h}_{\mathrm{r}}=\$ 5$ per unit per unit time, $\mathrm{B}=10$ units, $\mathrm{L}=\$$ $50, \eta=0.2, \delta=2, \alpha=0.005, \beta=1, \quad \mathrm{~g}(\mathrm{P})=0.0005 \mathrm{P}, \mathrm{f}(\mathrm{u})=1 /((0.2-0.03)), 0.03<\mathrm{u}<0.2, \mathrm{n}=3, \mathrm{D}=10$ units

Then, the optimal results for Stakelberg theory are $P_{m}^{*}=18.12$ units, $Q_{m}^{*}=93.29$ units, $E A C_{S}^{*}=$ $\$ 568.56, E A C_{m}^{*}=\$ 5809.42, E A C_{r}^{*}=\$ 1798.96$ and the total system cost of the chain is $\$ 8177.05$. The optimal results for collaborating system are $P^{*}=17.71$ units, $Q^{*}=111.41$ units and the total system cost of the supply chain is $\$ 8166.53$.

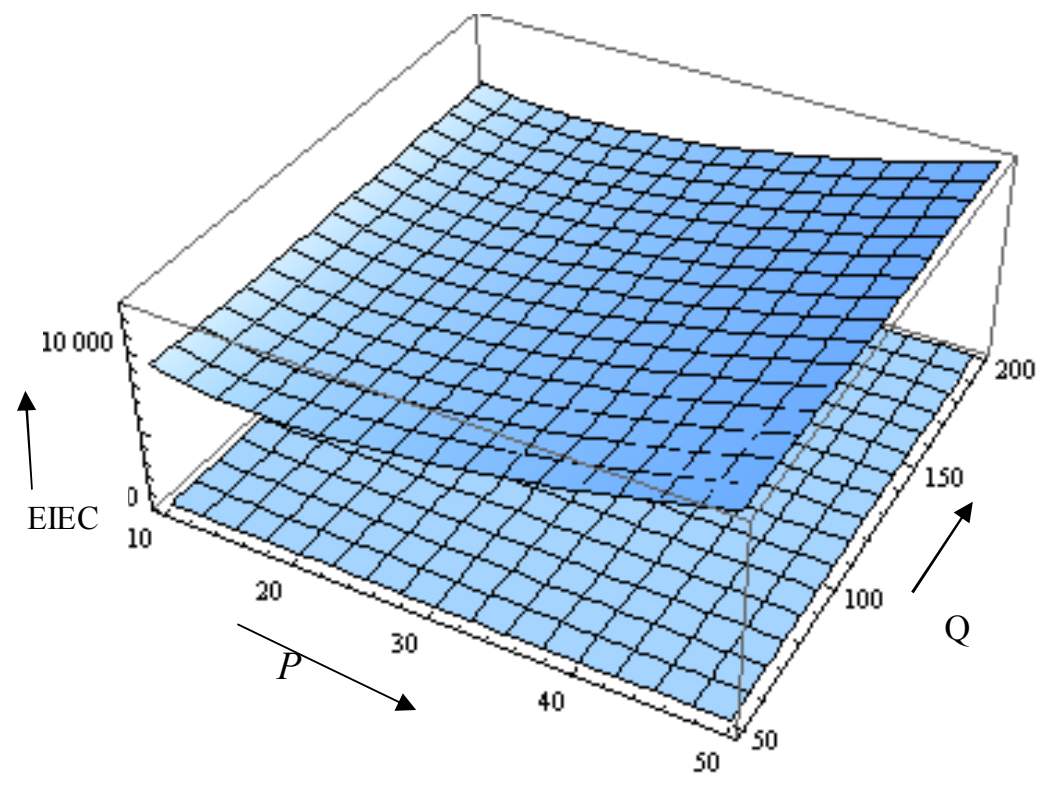

Fig. 2(a)

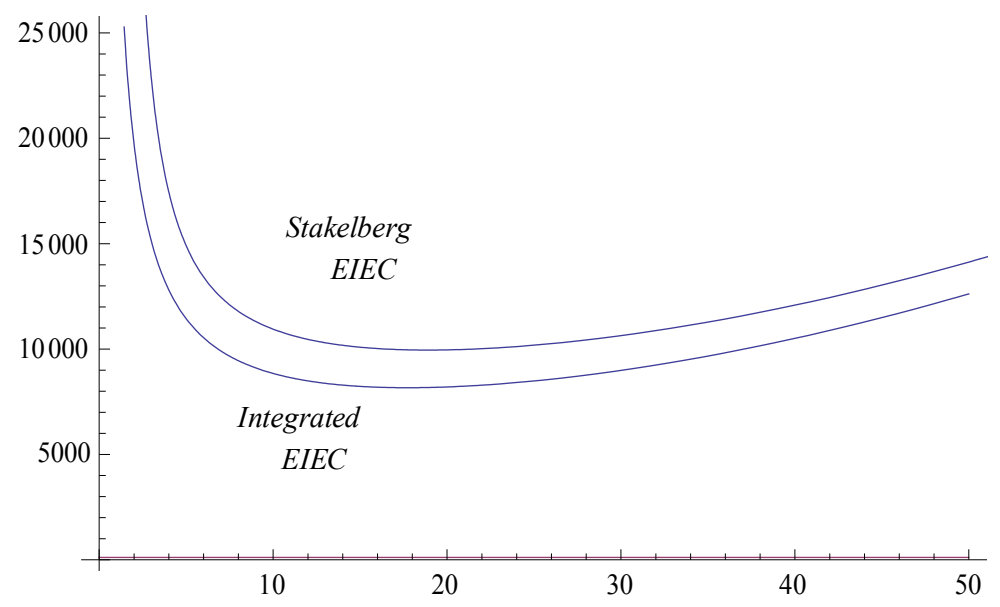

Fig. 2(b). Cost w. r. t. Production rate P

\section{Sensitivity Analysis}

1. When the holding cost of supplier $\left(h_{s}\right)$ is decreased, production rate decreases and the optimal ordering size increases while expected average integrated system cost decreases and this cost is smaller 
than expected total system cost by Stakelberg approach. Increase of $h_{s}$, production rate increases, the optimal ordering size decreases and expected average integrated system cost increases.

Table 1

The results of sensitivity analysis

\begin{tabular}{|c|c|c|c|c|c|}
\hline & $\begin{array}{l}\text { Value of } \\
\text { Parameters }\end{array}$ & $\begin{array}{c}\text { Optimal Production Rate } \\
\left(\mathrm{P}^{*}\right) \\
\text { (Integrated System) }\end{array}$ & $\begin{array}{c}\text { Optimal Ordering Size } \\
\left(\mathrm{Q}^{*}\right) \\
\text { (Integrated System) }\end{array}$ & $\begin{array}{c}\text { EIAC } \\
\text { Integrated Cost }\end{array}$ & $\begin{array}{c}\text { EIAC } \\
\text { Integrated Cost } \\
\text { Stekelberg App. }\end{array}$ \\
\hline \multirow{3}{*}{$\mathrm{h}_{\mathrm{s}}$} & 1.5 & 17.55 & 120.30 & 8127.17 & 8177.05 \\
\hline & 3 & 17.71 & 111.41 & 8166.53 & 8177.05 \\
\hline & 4.5 & 18.05 & 104.35 & 8202.88 & 8177.05 \\
\hline \multirow{3}{*}{$\mathrm{h}_{\mathrm{m}}$} & 2 & 17.91 & 120.50 & 8125.91 & 8128.46 \\
\hline & 4 & 17.71 & 111.41 & 8166.53 & 8177.05 \\
\hline & 6 & 17.54 & 104.28 & 8203.82 & 8233.32 \\
\hline \multirow{3}{*}{$\mathrm{h}_{\mathrm{r}}$} & 2.5 & 17.70 & 125.79 & 8104.98 & 8177.05 \\
\hline & 5 & 17.71 & 111.41 & 8166.53 & 8177.05 \\
\hline & 7.5 & 17.72 & 101.41 & 8219.62 & 8177.05 \\
\hline \multirow{3}{*}{$\mathrm{u}$} & 0.1 & 17.61 & 103.87 & 7309.05 & 7323.21 \\
\hline & 0.2 & 17.71 & 111.41 & 8166.53 & 8177.05 \\
\hline & 0.3 & 17.80 & 118.79 & 9146.63 & 9276.03 \\
\hline \multirow{5}{*}{$\delta$} & 1.0 & 105.38 & 107.23 & 6339.82 & 6409.86 \\
\hline & 1.5 & 35.32 & 108.88 & 7124.38 & 7168.90 \\
\hline & 2.0 & 17.71 & 111.41 & 8166.53 & 8177.05 \\
\hline & 2.5 & 11.02 & 114.72 & 9343.10 & 9430.70 \\
\hline & 3 & 7.80 & 118.69 & 10562.40 & Not Convergent \\
\hline \multirow{3}{*}{$\eta$} & 0.1 & 22.32 & 110.35 & 7680.88 & 7703.59 \\
\hline & 0.2 & 17.71 & 111.41 & 8166.53 & 8177.05 \\
\hline & 0.3 & 15.47 & 112.17 & 8507.17 & 8680.77 \\
\hline \multirow{5}{*}{$\beta$} & 0.25 & 17.71 & 111.43 & 8166.44 & 8176.01 \\
\hline & 1 & 17.71 & 111.41 & 8166.53 & 8177.05 \\
\hline & 2 & 17.70 & 111.07 & 8168.17 & 8187.54 \\
\hline & 3 & \multicolumn{4}{|c|}{ Results are failed to converge to a solution } \\
\hline & 4 & 14.87 & 78.89 & 8461.66 & 8649.50 \\
\hline
\end{tabular}

2. When the holding cost of supplier $\left(h_{m}\right)$ is decreased, production rate increases and the optimal ordering size increases while expected average integrated system cost decreases and this cost is smaller than expected total system cost by Stakelberg approach. Increase of $h_{m}$, production rate decreases, the optimal ordering size decreases and expected average integrated system cost increases.

3. When the holding cost of supplier $\left(h_{r}\right)$ is decreased, production rate decreases and the optimal ordering size increases while expected average integrated system cost decreases and this cost is smaller than expected total system cost by Stakelberg approach. Increase of $h_{r}$, production rate increases, the optimal ordering size decreases and expected average integrated system cost increases.

4. Changes of defective items parameter $u$ at supplier have positive impact, i.e., production rate, optimal ordering size and the expected average integrated system cost increase when $u$ increases and decrease when $\alpha$ decreases.

5. Die cost parameters $\eta, \delta$ are highly sensitive for production rate and the expected average integrated system cost; they have positive impact for all costs. The expected average integrated system cost is smaller than expected total system cost by Stakelberg approach in all changes of $\eta, \delta$.

6 . With the increasing product reliability parameter $(\beta)$, production rate decreases and the optimal ordering size also decreases while the expected average integrated system cost increase.

From the Table 1, we get the expected average integrated system cost always smaller than expected total cost by Stakelberg approach in this model. 


\section{Conclusion}

In this study, we have derived a three-echelon supply chain involving supplier, manufacturer and retailer with replenishment lot size of supplier and production rate of manufacturer being the decision variables. It is assumed that the cycle time at each stage is equal. The cost of idle time of supplier and partial backlogging are also considered. At each stage, the defective items at supplier level are sent back after completion of inspection at one lot with sales price. After a random time, the process may shift to "out-of-control" state from "in-control" state during the production run and may generate imperfect quality items. The imperfect quality items are reworked at a cost immediately. Finally, an average expected system cost function of the manufacturer is minimized by taking the manufacturer as main component of system (Stakelberg) of the supply chain and the supplier and retailer are secondary. The collaborating system cost function, combining the average cost of supplier, manufacturer and retailer, is also minimized. From numerical results, we have observed that the integrated system cost function provides more less cost compared to the cost of the whole chain by Stakelberg approach. A numerical example is studied to illustrate the proposed model. The sensitivity of the solution to changes in the values of different parameters has also been discussed.

The major contribution of the supply chain is mainly in the inclusion of the manufacturer. We consider shortage for retailer, $\mathrm{n}$ small replenishment lot size, unit production cost and total number of defective items through more reliable function in the three echelon supply chain. For further research, this paper may be extended by considering the uncertain demand at each stage and multi-supplier and multiretailer levels may also be introduced in this model.

\section{Acknowledgement}

The authors would like to thank the anonymous referees and editors for their detailed and constructive comments and the first author is very much thankful to the council of scientific and industrial research (CSIR) New Delhi, India for the financial assistance in the form of Junior Research Fellowship (JRF).

\section{References}

Banerjee, A. (1986). A joint economic lot size model for purchaser and vendor. Decision Sciences, 17, 292-311.

Ben-Daya, M. \& Hariga, M. (2000). Economic lot scheduling problem with imperfect production processes. Journal of the Operational Research Society, 51, 875-881.

Biswas, P. \& Sarker, B.R. (2008). Optimal batch quantity models for a lean production system with incycle rework and scrap. International Journal of Production Research, 46, 6585-6610.

Clark, A.J. \& Scarf, H., (1960). Optimal policies for a multi echelon inventory problem. Management Science, 6, 475-490.

Cheng, C. E. (1989). An economic production quantity model with flexibility and reliability considerations. European Journal of Operational Research, 39, 174-179.

Chung, K.J. \& Hou, K. L. (2003). An optimal production run time with imperfect production processes and allowable shortages. Computers \& Operations Research, 20, 483-490.

Chiu, Y.S.P., Ting, C.K., Cheng, C.B. \& Lin, F.Y. (2007). Alternative approach for realistic lot size problem with random scrap rate and backlogging. WSEAS Transactions on Mathematics, 6, 736740.

Cárdenas-Barrón, L.E., (2008). Optimal manufacturing batch size with rework in a single stage production system - A simple derivation. Computers and Industrial Engineering Journal, 55, 758765.

Cardenas-Barron, L. E. (2009). Economic production quantity with rework process at a single-stage manufacturing system with planned backorders. Computers and Industrial Engineering, 57, 11051113.

Eroglu, A. \& Ozdemir, G. (2007). An economic order quantity model with defective items and shortages. International Journal of Production Economics, 106, 544-549. 
Jaber, M.Y. \& Guiffrida, A. L. (2004). Learning curves for processes generating defects requiring reworks. European Journal of Operational Research, 159, 663-672.

Khouja, M. \& Mehrez, A. (1994). An economic production lot size model with imperfect quality and variable production rate. Journal of the Operational Research Society, 45, 1405-1417.

Khouja, M. (1999). A note on deliberately slowing down output in a family production context. International Journal of Production Research, 37, 4067-4077.

Lee, H. L. \& Rosenblatt, M. J. (1987). Simultaneous determination of production cycle and inspection schedules in a production system. Management Sciences, 3, 1125-1136.

Liao, G. L. (2007). Optimal production correction and maintenance policy for imperfect process. European Journal of Operational Research, 182, 1140-1149.

Lo, S.T., Wee, H.M. \& Huang, W. C. (2007). An integrated production inventory model with imperfect production processes and Weibull distribution deterioration under inflation. International Journal of Production Economics, 106, 248-260.

Lee, H. H. (2008). The investment model in preventive maintenance in multi-level production systems. International Journal of Production Economics, 112, 816-828.

Liao, G. L. Chen, Y. H. \& Sheu, S. H. (2009). Optimal economic production quantity policy for imperfect process with imperfect repair and maintenance. European Journal of Operational Research, 195, 348-357.

Pal, B., Sana, S. S. \& Chaudhari, K. (2012). Three-layer supply chain production inventory model for reworkable items. Applied Mathematics and Computation, 219, 530-543

Pal, B., Sana, S. S. \& Chaudhari, K. (2012). A multi-echelon supply chain model for reworkable items in multiple-markets with supply disruption. Economic Modelling, 29, 1891-1898.

Rosenblatt, M. J. \& Lee, H. L. (1986). Economic production cycles with imperfect production processes, IIE Transactions, 18, 48-55.

Salameh, M. K. \& Jaber, M. Y. (2000). Economic production quantity model for items with imperfect quality. International Journal of Production Economics, 64, 59-64.

Sheu, S. H., Chen, J.A., (2004) Optimal lot-sizing problem with imperfect maintenance and imperfect production. International Journal of Systems Science 35, 69-77.

Sarker, B. R., Jamal, A. M. M. \& Mondal, S. (2008). Optimal batch sizing in a multi-stage production system with rework consideration, European Journal of Operational Research, 184, 915-929.

Sana, S. S. \& Chaudhuri, K. S. (2010). An EMQ model in an imperfect production process. International Journal of Systems Science, 41 (6), 635-646.

Sana, S. S. (2010). A production-inventory model in an imperfect production process. European Journal of Operational Research, 200 (2), 451-464.

Sarkar, B., Sana, S. S. \& Chaudhuri, K. S. (2010). Optimal reliability, production lot size and safety stock in an imperfect production system. International Journal of Mathematics in Operational Research, 2, 467-490.

Sana, S. S. (2011). A production-inventory model of imperfect quality products in a three-layer supply chain. Decision Support Systems, 50, 539-547.

Sarkar, B. (2012). An inventory model with reliability in an imperfect production process. Applied Mathematics and Computation, 218, 4881-4891.

Singh, N., Vaish, B. \& Singh, S. R. (2012). An economic production lot-size (EPLS) model with rework and flexibility under allowable shortages. International Journal of Procurement Management, 5(1), 104-122.

Wang, C. H. (2004). The impact of a free-repair warranty policy on EMQ model for imperfect production systems. Computers \& Operations Research, 31, 2021-2035.

Yeh, R. H., Ho, W. T. \& Tseng, S. T. (2000). Optimal production run length for products sold with warranty. European Journal Operational Research, 120, 575-582. 